ESJ Social Sciences

\title{
Territorial Marketing Applied of Great Events: The Case Study of Cortina d'Ampezzo
}

\author{
Silvia Fedrici, (MA, Researcher of Tourism Marketing) \\ Elisa Rancati, (PhD, MA, Assistant Professor of Tourism Marketing) \\ University of Milan-Bicocca, Milan, Italy
}

Doi:10.19044/esj.2021.v17n5p37

Submitted: 07 December 2020

Accepted: 03 February 2021

Published: 28 February 2021
Copyright 2021 Author(s)

Under Creative Commons BY-NC-ND

4.0 OPEN ACCESS

Cite As:

Fedrici S. \& Rancati E. (2021). Territorial Marketing Applied of Great Events: The Case Study of Cortina d'Ampezzo. European Scientific Journal, ESJ, 17(5), 37.

https://doi.org/10.19044/esj.2021.v17n5p37

\begin{abstract}
Territorial marketing and great events marketing is generally considered by academics and professionals as a discipline with dynamic and not fully distinct fields. This study aims to develop research in these fields, examining the impacts of territorial marketing on a tourism destination during a great event. Data collected from tourists in Cortina d'Ampezzo (Italy) demonstrates that this destination became famous following territorial marketing used for the Olympic Games in 1956 and its attractiveness is still alive, so much so that it has been chosen once again to host the 2026 Winter Olympic Games. This study underlines how territorial marketing has created a tourism destination that can attract tourists regardless of the great event.
\end{abstract}

Keywords: Great events, territorial marketing, Cortina d'Ampezzo

\section{Introduction}

The marketing of great events starts from the analysis of opportunities and risks, in order to pursue various short, medium, and long-term purposes, by satisfying the interests of the multiple stakeholders involved. Given the growing competition, a marketing-oriented approach to event management needs to differentiate its market, with the goal of attracting the visitor or participant towards a mostly superfluous activity, creating the illusion that it is fundamental for one's lifestyle. In recent years new types of marketing that are more specific to each sector have been studied and put into practice. Many 
are the type of marketing techniques that involve great events depending on the type of the latter (e.g. sporting, cultural, musical), but the marketing mix and above all the territorial marketing for its success is increasingly important.

\section{Literature review}

\section{The great events}

Although the first great event mentioned is the Olympics in Athens in $776 \mathrm{BC}$, researchers have not come up with a definition of a great event that is shared, unique, and coherent. Definitions of great events are different and often conflicting ones have been found. As they are increasingly widespread, some definitions of great events follow: "as recognizable at a specific point in time for the intention and rituals carried out in order to satisfy needs" (Getz, 1991, p. 22); "specific rituals or celebrations that are consciously programmed and implemented to mark somehow special occasions". (McDonnell, 1999, p. 14); "public event made known in order to attract attention and to arouse interest in the company or body that organizes it and which provides for the participation of an audience interested in the contents displayed" (Cocco and Pozzi, 2001, p. 45); "activities that allow you to reach a target in a specific place and time; like meetings where messages are addressed and recreational activities take place" (Behrer and Larsson, 1998, p. 34). From this plurality of definitions, an event can be defined as an initiative of limited duration in time and of various nature (e.g. sporting, cultural, institutional, economic) that can attract many people. Most of the time, an event involves investments and the modification of the urban fabric in a most permanent way. It is usually successful if there will be great media interest if the percentage of tourists will be greater than the local subjects, if tourist stays will be for more nights and if tourists will be willing to travel a long distance to reach the event concerned. "Although all types of planned events have tourism potential, even the smallest wedding or reunion, larger events dominate in the literature and in event tourism development" (Getz, 2007, p. 25). There are several ways that can define a great event and make it such: the size, the drawing power, the theme, the frequency, the duration, and the role of the public. Considering the dimension, the consequence of the drawing power (the power to draw attention), and the role of the public, there are mega-events, special events, hallmark events and community events (Roche, 2004, p. 40). The mega-events are defined as an "important event, recurring or organized only once, of short duration, which serves to increase awareness, charm, economy of a short and/or tourist destination long term. The success of these events depends on their success, uniqueness, importance or ability to create interest and attract attention" (Ritchie, 2009, p. 41). Each event can have a theme or multiple themes (monothematic or polythematic event): celebrations, art and entertainment events, business and commercial events, sports competitions, 
educational and scientific events, recreational events, political/civil events, private events (Getz, 2005, p. 15). As for frequency, an event varies according to its organizational characteristics: it can take place once a year or once every few years on dates. Furthermore, an event can be distinguished by duration: it can be different or it can remain fixed. All these classifications are used to understand the aim of a great event and the impacts it will have on a territory.

\section{The territorial marketing of great events}

Any great event, whether it was successful or not, leaves a trace of its passage in the territory that hosted it. The most significant impacts are visible even after years and will give added value to the destination. Initially, the experts to evaluate whether an event was successful or not, only considered the economic aspect; it has been since the mid-2000s that other impacts have been taken into consideration and become fundamental. If the economic evaluations allow measuring a part of the "tangible" and immediate return that a mega-event can leave on the territory, it is also true that they are not sufficient to fully evaluate their benefits, especially of an intangible and longterm nature. From this, it seems more appropriate to try to identify other effects, related to the tourism sector, environmental and social. These impacts have different echoes, but always concern the following areas: economic, socio-cultural, psychological, physical-environmental, political, and tourism. No matter what the impact will weigh most on the place where the great event will take place, everyone will contribute to creating a new image for the territory itself and the way of life of the resident people. Before carrying out a great event, all these effects must be taken into consideration and the various variables and repercussions both in the present and in the future must be hypothesized and considered. In fact, if it transpires that the event can only bring negative aspects, it will be necessary to rethink its location and performance. All the following variables must be taken into consideration before organizing a great event: potential risk for the destination; probability of success; compatibility with existing locations; competences of the event managers; potential benefits for the territory; potential environmental impacts; forecast of the number of tourists; consistency of the event with the image of the destination. Each territory, in which the decision is made to make it become tourist, will have impacts and strong changes over the years. But the main difference of a place that has become a tourist attraction for major events is that these changes will take place more quickly and substantially. Numerous infrastructures will be created in a short time as money used for the occasion is used; tourists will arrive in masse and the town or city will have to be able to welcome these people. In a tourist resort, however, people will gradually come and the local population will have time to build hotels and other services and to adapt gradually, without quickly upsetting the balance of the 
community. Each impact can have benefits and costs on any local community that is taken into consideration: their weight varies according to the event and its organization.

\section{Methodology}

Cortina d'Ampezzo is a village located in the province of Belluno (Veneto) and it is part of the Dolomiti Superski area. This village has a huge tourism attractiveness due to its history and to the great events hosted in the land. Although it was already known in the previous centuries, Cortina d'Ampezzo began its golden age when it was chosen to host the Winter Olympic Games of 1956, becoming visible internationally and increasing exponentially in tourism. This edition was a success for its organization and for its territorial marketing policy. The organizers were able to attract people by broadcasting the Cortina Winter Games on television for the first time in the history of the Olympics: it was an innovative step to relaunch the destination, creating attractiveness for years to come. It should be remembered, in fact, that it is from the second half of the twentieth century that people begin to practice mass tourism. Furthermore, these Winter Games led to the construction and modernization of the ski facilities, the ice rink, the Olympic downhill run, and the Olympic ski-jump: all these structures were not abandoned after the event, but Cortina d'Ampezzo was able to keep them. It also hosted 25 editions of the Women's Alpine World Cup, numerous Nordic skiing events, the Snowboard FIS World Cup, the Freeride World Cup. Furthermore, the 1956 Olympic Winter Games are proof that the marketing carried out for their promotion was successful because nowadays most people remember them and know that in that year the Olympics were held in Cortina d'Ampezzo, as demonstrated by the survey.

The survey for data collection was carried out through a questionnaire of 15 questions. It aims to solve some research questions, namely whether Cortina d'Ampezzo is known as a tourist destination and for the 2026 Winter Games. The sample is composed of 457 people. The structure of the following research is mostly based on a qualitative method, since they "are used to address research questions that require explanation or understanding of social phenomena and their context" (Richards and Munsters, 2010, p. 34). In addition to the qualitative method, the triangulation method is used, which is a set of systematic observations and surveys. In particular, systematic observation consists of "collecting information regarding the quality of the experience, perceived value, satisfaction and future behavioural intentions", but also "collecting information about the numbers" (Richards and Munsters, 2010, p. 43). In detail, in this case, the term experience refers to the knowledge of the destination or not. Furthermore, since it is a detail of an event that has not yet occurred, the future intentions and the perceived value are present in 
the part of the questionnaire in which personal opinions are asked about the event and the intentions from a tourist point of view in visiting the destination or not. Also, this method is perfect for this research case because it "enhances a study's generalizability" (Richards and Munsters, 2010, p. 56). The questionnaire was created using "Google Forms" and it was disseminated on social networks and via e-mail contacts and, thanks also to the help of word of mouth, it was possible to obtain a fairly considerable number of responses. It was circulated starting from 8 June 2020 and it was possible to reply to it until 8 July 2020. Since the Milan-Cortina Olympics will involve three Italian regions (Lombardy, Veneto and Trentino Alto-Adige), the people who live in these geographical areas were chosen as a sample, to comment on people's ideas (for and against) in a more targeted way, who will touch this Great Event first hand. In particular, about $8 \%$ of people live in Veneto, 2\% in Trentino and the rest (most of the sample) live in Lombardy. Furthermore, as regards the demographics of the sample, people aged between 16 and 75, of which $57 \%$ of them are women, answered.

\section{Results}

Returning to the 1956 Olympics, it appears from the questionnaire that 45.9\% know that Cortina d'Ampezzo was the protagonist of the great event. This is a very relevant figure, considering that about sixty years have passed since the great event and $66.4 \%$ of the people who answered the questionnaire have never visited Cortina d'Ampezzo.

Thanks to this attractiveness in the winter season for snow lovers and to the historical, climbing, landscape and luxury tourism sites, Cortina d'Ampezzo has had 6000 inhabitants during the year and it can host around 100,000 people during the high season (statistica.provincia.belluno.it). The hotels built during the Winter Games of 1956 were not only able to respond to the demand of tourists during that period but thanks to the echo that they gave from the Games, they were able to multiply during the years, without ever having a decline. It is interesting that tourism and the hotel sector have created many jobs, not only for the inhabitants of the area but above all for people from all over Italy. Cortina d'Ampezzo has been able to adapt and evolve, always remaining the flagship of the Dolomites and a very renowned location at an international level, both for the numerous sports activities carried out at competitive levels, both as a luxury destination. This is also due to its ability to carry out territorial marketing that has always been able to put the spotlight on Cortina d'Ampezzo, so much so that it has been chosen for another great event, namely the Milan-Cortina 2026 Winter Olympic Games.

From the survey questionnaire carried out, Cortina d'Ampezzo appears to be a well-known location in the sample. In fact, most people turn out to have never visited it, but they know exactly where it is located, they know that it is 
a mountain resort and in particular, a destination considered a luxury. In detail, 505 people out of 547 know Cortina d'Ampezzo and only 183 have visited it: this is a success at the level of diffusion that all the territorial marketing in Italy has had. The questionnaire was carried out based on a sample of people Italian and non-foreign and although the town has many foreign tourists, that part of the inherent data has not been taken into consideration. As further confirmation, it should be noted that almost all of the samples (99.6\%) were able to place Cortina d'Ampezzo in a mountain destination and $89.9 \%$ were able to recognize it as a luxury destination. This is visible from the results of the last question: only $8 \%$ of people do not have their own opinion on whether or not it is a renowned and luxury destination. All these data show how a small town in the middle of the mountains has managed to prevail over the others, reaching an international reputation in the last two centuries: all thanks to the ability of territorial promotion, to the opening in the tourism sector and the numerous events held in the locality. Cortina d'Ampezzo has been a destination of great tourist attraction in the last century, even becoming a luxury destination. Its success is certainly due to the environment in which it is located, but what differentiates it has been the ability to enhance its territory. In northern Italy, there are many villages in the Dolomites that resemble it, but which are not so renowned. Cortina d'Ampezzo has been able to make tourism its trump card and this is also due to its organization and territorial promotion. Although it is not possible to compare what territorial marketing is and does today with all its territorial promotion works, in Cortina d'Ampezzo a form of advertising the town was already taking place at the beginning of the twentieth century. Most of the people use information technology to choose their tourist destination and for this reason, the choice to briefly dwell on the part dedicated to social networks. In fact, there are many pages dedicated to Cortina d'Ampezzo, both on Facebook, but above all on Instagram, which very often publish updated photos of the area and events that are scheduled there. This is a modern way to promote the territory and it is a part of territorial marketing: it turns out to be a very important channel since it has more than 42 thousand people as regular users (source: https://www.dolomiti.org/it/cortina/). In reality, however, it reaches a larger portion of people, since not all of them officially "follow" the page, but they can consult it. And it is precisely the power that the web world has to reach people in every home and place, the reason why Cortina d'Ampezzo also has its own official internet page, with the same name as the social page, which can be consulted in English or in Italian. The website is well structured and very simple and intuitive for navigation: it is constantly updated and includes any information that is possibly useful both for the inhabitants and, above all, for tourists. In the initial bar, in fact, a visitor can choose between the following options: "discover Cortina", "experiences", "where to sleep", "food and wine", "events". This website is cared for down to 
the smallest detail and is "tourist" proof, where visitors can find much information. In particular, in addition to general information about the country, there is a list of activities that can be carried out. By clicking on the "where to sleep" option, a visitor can instead find a complete list of hotels and non-hotels. Browsing the Internet, looking for information about Cortina d'Ampezzo, one realizes that in reality the image of Cortina d'Ampezzo is not only followed by the official page, but there is even an organization called "Foundation", for the organization of the 2026 Olympic Winter Games. However, all these sites always head to the official website of "Cortina Marketing". The latter also has the same structure and graphics: territorial marketing is already a very strong and structured point in the region. In fact, in addition to the specific, there is a paper booklet created by Cortina Marketing with all the possible and imaginable information and territorial promotion. It recalls the online model; it is very simple and just as well structured and easy to understand: it can be found at the info point in Cortina d'Ampezzo and in some places around the city. In addition, some shops, bars, restaurants, have pasted the logo for the 2021 Games in their windows, a form of promotion and information for tourists: the people of Ampezzo are now giving priority to this event. Referring to the questionnaire carried out, at this point, it is correct to focus on question number 6 , in which people are asked how they became aware of the existence of Cortina d'Ampezzo. It is a very important aspect to see in which sectors territorial promotion marketing acts and its strengths and weaknesses. The question had the possibility of multiple answers, as there may be many factors that influence knowledge, for example, "I knew the destination by word of mouth and now I have a second home in Cortina d'Ampezzo". It is important to note that among the data collected, there is a small percentage who know Cortina d'Ampezzo very well because they live there or have a second home: the questionnaire was widely disseminated for having very diversified answers. Furthermore, it should be remembered that only 139 of the people visited the location. It is evident that most of the people, almost 50\%, have declared that they know Cortina d'Ampezzo thanks to advertising, that is, both thanks to the media channel (news, documentaries, advertising), and thanks to the information taken from the web (sites, social networks, ads) and from various advertisements in magazines and newspapers. The first method used by a locality for its promotion is still today the same and the most effective in the twenty-first century: it is a fundamental key aspect for the success of good territorial marketing planning. This way of promotion, in fact, reaches people of all age targets: from the child who sees an interesting advertisement to the boy who is passionate about the mountains, to the adults who watch different programs on television. Almost a fifth of people who answered the questionnaire specified that they became aware of the place through social networks: 
probably some of these people are among those who also voted for the answer previously commented on "advertising", obviously excluding the youngest and the oldest, categories that do not use social networks much. The latter has proved to be a fundamental tool in the last twenty years since any place, place or information can be found there and are used extensively for tourism promotion. In addition, many places are visited very often by famous people who are very active on their virtual profiles and for this reason, they reach a very wide audience, and more or less voluntarily influence it and encourage the fan to visit the same places or to inquire about them. And it is precisely for this reason that more and more often, many hoteliers, restaurateurs or the same places in a general sense welcome famous people, who are hosted in luxury locations for free with the sole purpose of local promotion: Cortina d'Ampezzo is among these places. Another very important data on the discussion on the efficiency of the promotion is that concerning travel agencies: less than $8 \%$ of the voters became aware of the location through this medium. This result is a symptom of the fact that fewer and fewer people use agencies to plan a trip from scratch, but they organize it online or, if they use the agency, very often they already have very clear ideas about the type of holiday they want to do: agency in a world so technological and now full of stimuli and media information take a back seat compared to almost forty years ago. This fact is reinforced by the fact that, as previously mentioned, 256 people became aware of Cortina d'Ampezzo thanks to advertising and, among the 457, 208 people knew it by word of mouth. Finally, another very important data for the territorial marketing of the Great Events are the 97 people who became aware of Cortina only and exclusively thanks to the Winter Olympic Games (those of 1956 or the future ones of 2026). Considering that the first games took place more than 50 years ago and there are still 6 years to go for the next, almost $20 \%$ of the people involved in the survey is an important figure for the promotion and visibility of both the location and the Great Event. This figure is even more important since 218 of the sample already knows Cortina d'Ampezzo because of their passion for winter sports: the 97 people are strangers to this world and for which they learned about the Olympic Games, not because of their beloved sport. But only because of various advertisements.

The choice of the future holding of the Winter Olympic Games in Cortina was discussed and discussed in the editions of the news and in the newspapers in the weeks following the official announcement: many people became aware of the event more or less voluntarily. From the questionnaire carried out, in fact, to the question "in 2026, Cortina has been chosen for", it turned out that $74.8 \%$ of the voters were aware of the Great Event. $24.1 \%$, on the other hand, declare that they have no idea of what will happen and a small percentage are misinformed or otherwise respond incorrectly $(<1 \%)$. No 
wonder that a quarter of the voters are not aware of the Event, especially considering the fact that $95.4 \%$ do not even know that there is already an official website for the Milan Olympics - Cortina, which is continuously updated. This makes understand that probably $75 \%$ of the voters have come to know about the event because they know Cortina because they love to ski or in a completely casual way through the news and are not really interested or "touched" directly by the event enough to go to deepen an event that will take place in six years. In any case, on 9 December 2019 the managers of the organization of the Milan - Cortina 2026 Games created a webpage of the Milan Cortina Foundation with its official website: "MilanoCortina2026". It has the role of organizing, promoting, and managing all communication of the Event in compliance with the rules of the Olympic Charter and the Code of Ethics. The official website is well structured and recalls the colors and structure of the official Cortina d'Ampezzo page, seen previously. As soon as you enter the site, two key photographs of these Games are clearly visible in the foreground: the Duomo of Milan and a snow-capped mountain in the Dolomites. The Cortina logo is clearly visible at the top left, which will appear in the center of the screen whenever a new search session is being loaded within the site. In it, you will find the story of the following edition of the Games, the fundamental documents to be respected previously mentioned, the Agenda with the programs, the possibility to send questions, and the section dedicated to "work with us". In a specially updated section, there are all the news concerning the world of the Great Event of the Olympics in the world, such as the sale of the Five Circles designed by Pierre de Coubertin, or news on the Tokyo Olympics, or the social initiatives to promote Milan-Cortina, etc. It is a very important part because it "accompanies" those who consult the site in anticipation of the 2026 Olympic Games: it is very important to update in real-time and to have a very active page for promotion and dissemination in order to have an audience as wide as possible. In fact, remember that a Great Event to be successful must involve a large number of people. Immediately after the announcement regarding the assignment, there were debates, mostly of a political nature, regarding the decision to have the Olympic Games held once again in Italy and mostly in Cortina and the surrounding area. If the event is successful, it will certainly bring many regional and state profits, but the impacts, as seen in the second chapter, can be innumerable and not always predictable. For this reason, referring to the sample of 457 people, here below it is discussed the possible impacts based on the answers collected and on the opinions of these people involved. Based on the order followed in the second chapter to describe the impacts of a Great Event, the same order has been used here below in order to evaluate and comment on the opinions thanks to questions 13 and 14 of the questionnaire: economic, socio-cultural, psychological and cultural impacts. image, physical - environmental and 
tourism. As for the economic impacts on the area involved, $24.1 \%$ of voters think that there will be beneficial economic returns for residents, and only about $11 \%$ of the total believe that the money invested and that will be spent on this project will bring too little or no profit. As for jobs, more than $34 \%$ believe there will be a large number of new jobs and job opportunities, but 104 people (19\%), on the contrary, believe that once the Games are over there will be a lot of people unemployed and therefore on the balance of pros and cons, the Olympics do not actually bring a situation from which to profit.

Referring to question number 11 or the socio-cultural impact, it appears that $98.2 \%$ agree or in any case indifferent to hosting the Games in Italy and $91 \%$ of the total believe that there will be advantages for our State. In fact, this opinion should not be underestimated because, as we have seen, a Great Event to be successful must first of all have a popular consensus: without it, there can be many problems and the event will not be successful. Still, it must be emphasized that there is a percentage of voters (111 of the 457) who underlined the fact that the overcrowding of Cortina for the Games will not benefit the residents at all and will create discontent.

As for the psychological impact - of image, $24.9 \%$ believe that there will be a modernization of the image of the territory taken into consideration and $47.2 \%$ (a significant percentage taking into account that these questions were a multiple choice) believes that there will certainly be an enrichment at the level of the territory and consequently of image. Relevant figure is 55.6\%: these people claim that the Milan - Cortina 2026 Winter Olympics will give greater visibility at national and international level. Among the physical and territorial impacts, as noticed a little while ago, many believe that there will be an enrichment of the territory. More in detail, 196 people believe that the territory will benefit from the construction of new infrastructures that will modernize the territory, but on the contrary, many people are afraid that, despite the positive aspects, the territory and its ecosystem could suffer considerable damage: $33,1 \%$ fear this. Furthermore, $35 \%$ also believe that the new infrastructures will be abandoned after the Games and that this will obviously be damage at a territorial level. In reality, despite these are the responses of the users, a note must be made: the real problem of these games will not be the infrastructures in the first place, since there is great planning to protect the environment and waste, reusing pre-existing structures and by not concentrating most of the events in a small town like Cortina (for example, the initial ceremony will take place in Milan). The territorial problem and the real challenge of this Olympics will be the connections and being able to move around the territory in a calm and organized way, without creating disruption to traffic. In fact, below, it is visible on a map where the locations concerned and the possible connecting routes are located: only after the event, it will be possible to have certainty about the efficiency of transport and to get a more 
accurate comment. Among the data concerning the advantages of the Olympic Games, the highest, with 300 people who have selected the following answer, concerns the tourist impact. Most people think that there will certainly be a substantial increase in tourism demand in the area in 2026 and that this demand will continue to increase after the Olympics. It is the most positive impact analyzed so far, as on the other hand there are only 29 people who believe that there will be no tourist growth. These impacts are not, as mentioned above, predictable: the organizers will have already analyzed and will continue to monitor each of the following factors to ensure that these Winter Olympics are a success and will have more advantages over the disadvantages. The questionnaire carried out concerning the Cortina case study revealed the knowledge of this territory and the Olympics that will take place there in 2026. Thanks to multiple-choice questions, in which it was possible to briefly express one's opinion through the voice "other", it is possible to discuss and analyze people's opinions. Thanks to a large number of the sample, we can make a generalization and affirm, precisely, that Cortina is well-known and considered a luxury destination. Most people know it without ever having been there and this is a strong point for territorial marketing: the territory is known, in most cases unconsciously, by the majority of the population and this is thanks to the promotional works. territorial occurred over the years and as a legacy of the 1956 Olympic Games, very well exploited by the Italian country. As for the future of Cortina d'Ampezzo after the 2026 Olympic Games, nothing is yet known with certainty and everything that has been done is nothing more than a guess since there are many variables and unexpected events that can happen. Nevertheless, summarizing the key points of the questionnaire, the sample of people was asked as the last question to give a grade from 1 to 5 regarding various statements. Among these, it is important to underline that $57 \%$ of people believe that there is no better location to host the Olympic Games and, another positive fact, as many as 379 of the sample found themselves in "agreement" or "fully" agreement with the idea that Cortina will improve and enrich its territory thanks to the Games. Despite these two very positive points, there are just as two negative ones. In fact, most people have no particular interest in visiting Cortina, even after the Games: 284 show little interest and 102 declare themselves indifferent to the event. Furthermore, the most relevant aspect, in close contact with territorial marketing, concerns the point concerning the advertising of the Games: "In your opinion, are the Olympics well advertised?". Only 23\% respond positively to this question and it is to be considered an alarming figure since the success of a Great Event is based on reaching the widest possible audience. Despite this, as previously mentioned, these are personal opinions and the fact that the event is not yet so publicized may be due to the fact that it is an event that will take place six years and that previously there is the World Ski 
Championships Alpine in Cortina in 2021: surely there is a marketing organization, but we will see it only in a few years.

\section{Conclusion}

There are many kinds of large events around the world, each with different and distinctive characteristics. Whereas the success of a great event "depends on their success, uniqueness, importance or ability to create interest and attract attention" (Ritchie and Smith, 1991, p. 45), territorial marketing is an indispensable part of attracting resources and tourists in any geographical area. It is fundamental also for controlling the organization itself, the promotion, and the effects that the event will bring on the location involved. Focusing on the case analyzed in this paper, despite the low knowledge of the official channels of Cortina d'Ampezzo 2026, it is a well-known location since the beginning of the twentieth century, but it had its "golden years" and the arrival of numerous tourists only in following the 1956 Winter Olympics. The organization it had, the structures built, and therefore, summing it all up with a word, its "legacy", guaranteed the visibility and knowledge of the locality worldwide. Most likely, without the great event and its success, it would have remained a tourist destination, but not so well known and not so visible compared to many mountain villages in the same geographical area. The fact that Cortina d'Ampezzo has been chosen for the 2026 Winter Olympic Games is not only for its past but for its organization at a territorial level: it has been able to propose a cutting-edge project, which would not have been possible without a team that has followed in recent years every aspect of territorial marketing and therefore knows the territory perfectly. If its organization continues to be present even after the second Olympic Games and will be able to make the most of this opportunity, Cortina d'Ampezzo will reach an even higher level of quality as a tourist destination. All this goes to show how a place, mostly unknown to the world, can become a flagship of the tourism economy thanks to its organization and marketing promotion at a territorial level, created exclusively for a great event. For this reason, many states compete with each other to try to host a great event in their territory, be it an Olympics, an Expo, or any event of such large dimensions.

\section{References:}

1. Behrer, M. \& Larsson, A. (1998). Event marketing: att använda evenemang som strategisk resurs i marknadsföringen. Göteborg: IHM.

2. Bright, W. J. (1990). An introduction to scientific research. NY: Dover Publications.

3. Caroli, M. G. (2007). Il marketing territoriale. Milan: Franco Angeli. 
4. Cercola, R., Izzo, F., Bonetti, E. \& Masiello, B. (2010). Eventi e strategie di marketing territoriale. I network, gli attori e le dinamiche relazionali. Milan: Franco Angeli.

5. Cherubini, S., Bonetti, E., Iasevoli, G. \& Resciniti, R. (2009). Il Valore degli Eventi. Valutare ex ante ed ex-post gli effetti socio-economici, esperienziali e territoriali. Milan: Franco Angeli.

6. Cocco R. \& Pozzi, L. (2001). I servizi di base: l'organizzazione di eventi in Invernizzi, E., Relazioni pubblliche: le competenze, le tecniche e i servizi di base, Milan: Mc Graw-Hill.

7. Decrop, A. (2000). Triangulation in qualitative tourism research, Journal of Travel \& Tourism Marketing, vol. 7, n. 5.

8. Ferrari, S. (1997). Event Marketing: i grandi eventi e gli eventi speciali come strumenti di marketing. Padova: Cedam.

9. Furrer, P. (2002). Sustainable Olympic Games. A dream or a reality?, Bollettino della Società Geografica Italiana, serie XII, vol. 7, n. 4.

10. Galvani, A. (2018). Origine et mouvements de la main-d'ouvre touristique à Cortina d'Ampezzo (Italie), In Hommes et Terres du Nord, Tourisme et développement local et regional, Milan: Franco Angeli.

11. Gavinelli, L., Morra, M. C. \& Di Gregorio, A. (2019). Pre-event marketing and territorial governance: the case of Monza and Brianza province, Qualitative Market Research Journal, vol. 19, n. 2.

12. Getz, D. (1991). Festivals, Special Events and Tourism, NY: Van Nostrand Reinhold.

13. Getz, D. (2005). Event Management and Event Tourism, NY: Elmsford.

14. Getz, D. (2007). Event tourism: Definition, evolution, and research, in Literature on event tourism by event types, Alberta: Haskayne School of Business, University of Calgary.

15. Hanna, S. \& Rowley, J. (2010). Towards a strategic place brandmanagement model, Journal of Marketing Management, vol. 27, n. 56.

16. Mazzeo, G. (2008), Great Events: Indicators for Classification and their Impact on the Urban Systems, TeMA - Journal of Land Use, Mobility and Environment, vol. 1, n. 2.

17. McDonnell, I. (1999). Festival and special event management, Canada: John Wiley and Sons.

18. Percoco, M. (2019). Territorial economic and fiscal impacts of Milano-Cortina 2026, Milan: University of Bocconi Press.

19. Preuss, H. (2000). Economics of the Olympic Games: Hosting the Games 1972-2000, Petersham: Walla Walla Press. 
20. Quinn, B. (2009). Festivals, events and tourism, Ireland: Dublin Institute of Technology.

21. Richards, G. \& Munsters, W. (2010). Cultural Tourism Methods, Cambridge: Cabi.

22. Risitano, M., Sorrentino, A. \& Quintano, M. (2014). L'impatto dei mega eventi nella gestione strategica dei territori. Il caso America's Cup World Series di Napoli, Mercati e competitività, n. 3.

23. Ritchie, B. W. (2009). Crisis and disaster management for tourism. London: Channel View Publications.

24. Ritchie, J. R. B., \& Smith, B. H. (1991). The impact of a mega-event on host regon awareness: a longitudinal study. Journal of travel research, vol, 30 .

25. Roche, M. (2004), Mega events and modernity, London: Routledge.

26. Schnitzer, B. M. \& Haizinger, L. (2019), Does the Olympic Agenda 2020 Have the Power to Create a New Olympic Heritage? An Analysis for the 2026 Winter Olympic Games, Innsbruck: University of Innsbruck Press.

27. Teigland, J. (2011). Mega-events and impacts on tourism; the predictions and realities of the Lillehammer Olympics, Impact Assessment and Project Appraisal, Tourism Management, vol. 14, n. 2. 